\title{
SURVEY AND VIRTUAL RECONSTRUCTION OF ANCIENT ROMAN FLOORS IN AN ARCHAEOLOGICAL CONTEXT
}

\author{
L. Fazio ${ }^{1, *}$, M. Lo Brutto ${ }^{2}$, G. Dardanelli ${ }^{2}$ \\ ${ }^{1}$ Department Cultures and Societies, University of Palermo, Italy, leonarda.fazio@unipa.it \\ ${ }^{2}$ Department of Engineering, University of Palermo, Italy, (mauro.lobrutto, gino.dardanelli)@unipa.it
}

KEY WORDS: Virtual reconstruction, Archaeology, 3D Model, Close-range Photogrammetry, Structure-from-Motion.

\begin{abstract}
:
Despite the consistent development of approaches aimed at the virtual reconstruction of whole houses or archaeological monuments, the variety of technologies involved in virtual reconstruction procedures and the complexity of a rigorous process to provide validation models, seems to limit a univocal and shared standards adoption. For example, compared to the large number of contributions on the virtual reconstruction of whole architectures or cultural heritage sites, only a few works have proposed a rigorous workflow specific to mosaics and ancient floors and to their virtual reconstruction. The goal of this work is to present the first results on the virtual reconstruction of the "Temple of Isis" in Marsala (Italy); in particular, the work is aimed at the virtual reconstruction of the mosaic and the opus spicatum floor still preserved in situ. A close-range photogrammetric survey was carried out in order to provide a detailed floors 3D reconstruction; a structure-from-motion photogrammetry approach was employed to obtain a detailed 2D and 3D documentation with millimetric accuracy and high level of colour fidelity. Thanks to the photogrammetric products, accurate virtual restoration/reconstruction of the whole floor surfaces was conducted in a rigorous way and as close as possible to the historical reality.
\end{abstract}

\section{INTRODUCTION}

Virtual reconstruction (VR) of the archaeological monuments can be used to re-built in a $3 \mathrm{D}$ digital space buildings or whole archaeological sites in a particular moment of the past, but also to reconstruct the original appearance of single sculptures, paintings and objects no longer existing or partially preserved. VR is considered an effective tool to improve scientific quality research, supporting documentation and interpretative analysis for many archaeological projects (Demetrescu, 2018), e.g. restoration and anastylosis activities as in the case of destroyed monuments (Denker, 2017). Moreover, exploiting the advantages of immersive visualization (IV) and augmented reality (AR), VR can improve significantly the visitor's archaeological experience, creating movies, virtual tours, games applications (Younes et al., 2017) or integrating multi-temporal and geospatial datasets, for a narrative base to facilitate the landscape values comprehension by non-expert users (Brumana et al., 2018).

Guidelines for a shared and standardized approach to VR processes have been reported in "The London Charter" (The London Charter, 2009) and in "The Sevilla Principles" (The Seville Principles, 2011). These documents recommend to provide a visualization filter that allows the user to perceive what has been reconstructed, in order to ensure data transparency principle. In addition, they emphasize the importance of identifying and evaluating the relevant sources, the technological and theoretical processes in a structured way to ensure the intellectual integrity of digital visualization results.

Starting from this assumption, different standard practices have been proposed for VR activities. From a semantic/ontological point of view, tools and standards were proposed applying conceptual models, like CIDOC-CRM (Doerr, 2003) and CHARM (Gonzalez-Perez, 2012), that uses visual language to describe VR process (CHML, ConML). The Extended Matrix (EM), instead, employs a stratigraphic archaeological approach (Harris, 1979) to managing the re-constructive records in order to create a validation model for VR (Demetrescu, 2015); the next version of EM (ver. 1.1) provides guideline application through three steps: data collection, EM model creation, creation of 3D models. In particular, data collection aims to a 3D survey of the remains still in situ or special finds collected during the excavations, considered as "objective sources" (Demetrescu and Fanini, 2017). In this case, 3D documentation of the surveying elements assumes great relevance in order to achieve a more realistic setting and closer to historical reality, and especially in view of the potential re-use of raw data.

Specifically for mosaics and/or ancient floors, scientific literature has proposed limited contributions related to their VR. This depends on the fact that the VR of an archaeological floor is generally part of larger projects that aim to re-built entire city-block, houses or public monuments (Demetrescu et al. 2016; Agnello et al. 2015).

Despite a large number of standard approaches to the question of decorated surfaces recording, such as the mosaic ones, only a few works have proposed a standardized workflow between their survey and VR phase. Non-metric digital reconstruction could be used to simulate mosaic integration of losing parts using existing geometric patterns (Monti and Maino, 2018) and to create AR application able to recognize and trace the mosaic figures (Santachiara et al. 2018). No paper suggests a rigorous workflow on VR floors and this is due to the variety of technologies involved in VR procedures and the complexity of a rigorous process to provide validation models (Demetrescu, 2015). Further relevant aspects are linked to the intrinsic

* Corresponding author 
features of the recording objects, as the conservation state and the type of decoration, that define the degree of reliability/uncertainty of a VR product.

Shared best practices were established instead for ancient remains survey and for mosaics or ancient floor. Nowadays, people who work with VR can count on high-precision surveying instruments and highly automated processes. In the last two decades, photogrammetry (in particular the so-called "Structure-from-Motion photogrammetry") and terrestrial laser scanning (TLS) approach have become increasingly used and have reached high-quality standards for $3 \mathrm{D}$ archaeological surveys.

Photogrammetry and TLS was employed to document large scale sites (Hatzopoulos et al., 2017), single elements such as paintings (D'Amelio and Lo Brutto, 2009), frescoes, or mosaic/decorative floors preserving details accuracy with submillimetric precision $(<1 \mathrm{~mm})$ and high level of colour fidelity (Ajioka and Hori, 2014).

However, should be considered that, in particular conditions, such as floor surfaces, TLS reveal some limits: shadow cones in the "points cloud" due to the positioning of the laser scanner on the floor, low incidence angle that can occur between the instrument laser beam and the horizontal plane. These issues could be overtaken by mounting TLS on special support to obtain a better return signal from the surface (Gabrielli et al. 2017). Moreover, TLS shows some limitations due to the colour reproducibility. Photographic cameras integrated on TLS are often inadequate to reproduce rich compositions, as a mosaic or a fresco. No high-quality textures using the RGB values acquired by TLS can be created - despite is possible re-map "point cloud" value - without high-resolution images from an external camera. These conditions, together with the TLS survey cost and the time-consuming in term of work-field and data processing, gave preference for easier and cheaper available procedures, such as those based on images.

In contrast to the range-based systems, photogrammetry is commonly considered to be a cost-effective and versatile technique for 3D archaeological recording (Sapirstein and Murray, 2017). The technique showed a variety of applications ranging, from a large-scale survey using multiple platforms (Arza-Garcia et al., 2019) to the single elements survey of a building, allowing accurate and high-quality rendering in terms of both geometry and colour (Remondino et al., 2016).

Recently, the union of photogrammetry and computer vision (CV) has revolutionized archaeological survey approach (Aicardi et al., 2018). In some cases, the entire process can be performed automatically with no intervention by the human operator, eliminating complex pre-calibration procedures and providing automatic identification of a great number of connecting points (Remondino et al., 2017). Structure-fromMotion (SfM) workflow allows to extract three dimensional data and camera positions from a collection of images that represented an object or scene; through specific algorithm ("image-matching" procedure), a "dense point cloud" can be obtained, from which to extract high-resolution and texturized 3D models (comparable to those obtained using TLS in terms of density and resolution), DEM and high detailed ortho-image.

Image-based systems were applied to restoration and cataloguing of ancient mosaics, focusing on the shape and the orientation of each tessera (Benyoussef and Derrode, 2011) and a full-scale reconstruction (scale 1:1), evaluating limit and potentiality of SfM approach (Lo Brutto and Dardanelli, 2017). Also in the case of a very complex building with the interior surfaces totally covered by mosaics, such as in Byzantine age buildings, the survey can be carried out through image-based techniques (Adami et al., 2018).
The paper presents the first results of the research project for the virtual reconstruction of the so-called "Temple of Isis" inside the Archaeological Park of "Lilibeo" (Marsala, Southern Italy). In order to re-built the entire complex in a 3D digital environment, the first step was the VR of the preserved mosaic and opus spicatum floor, starting from 3D documentation. Work followed three steps:

1) Survey: photogrammetric survey to produce a very detailed 3D model of the ancient Roman floors;

2) Interpretation: identification of geometrical shapes and decorative pattern based on the ortho-image analysis;

3) Virtual reconstruction: VR in order to simulate hypothetical reconstruction surfaces starting from a modified ortho-image.

\section{THE "TEMPLE OF ISIS"}

The Archaeological Park of "Lilibeo" extended 28 ha inside the city of Marsala, preserves a considerable area of the ancient Lilybaeum (Figure 1). The ancient town was founded in the IV century B.C. by the Punic. Of the Roman Age city plan (II century B.C. - IV century A.D.), three city-blocks were excavated between 1939 and 2008, known as Insulae I, II and III. One of the most interesting buildings was discovered in the area of Insula III (Figure 2). It is a monumental complex interpreted as a sacred area dedicated to Isis goddess (Giglio et al., 2012). The building, which life started in the Republican period (II century B.C.), preserves the remains of the last phase of use, which occurred in the late-Imperial age (III - IV centuries A.D.) (Figure 3).

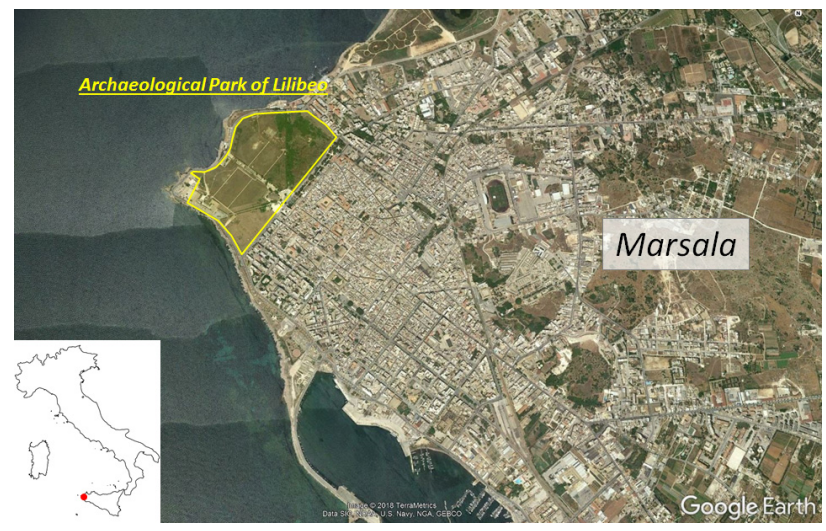

Figure 1. Archaeological Park of "Lilibeo" (from Google Earth(C).

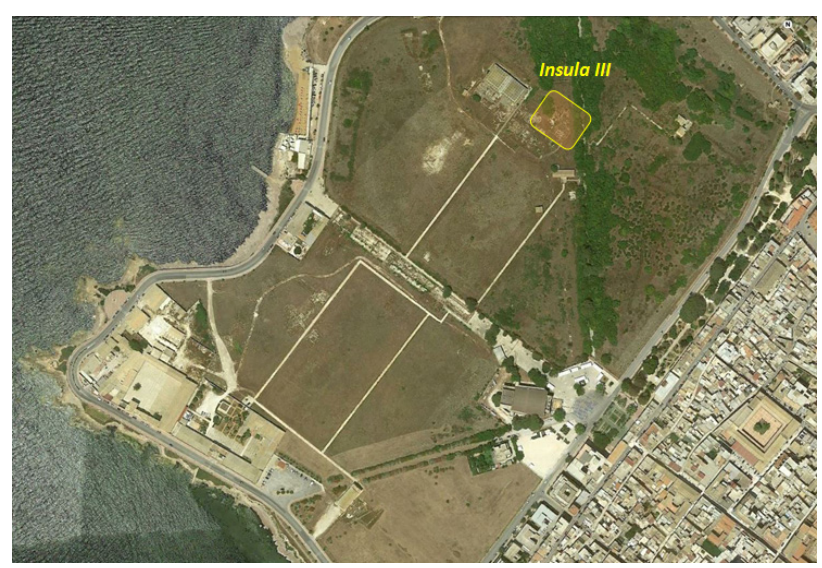

Figure 2. The area of the Insula III inside the Archaeological Park of "Lilibeo" (from Google EarthC). 


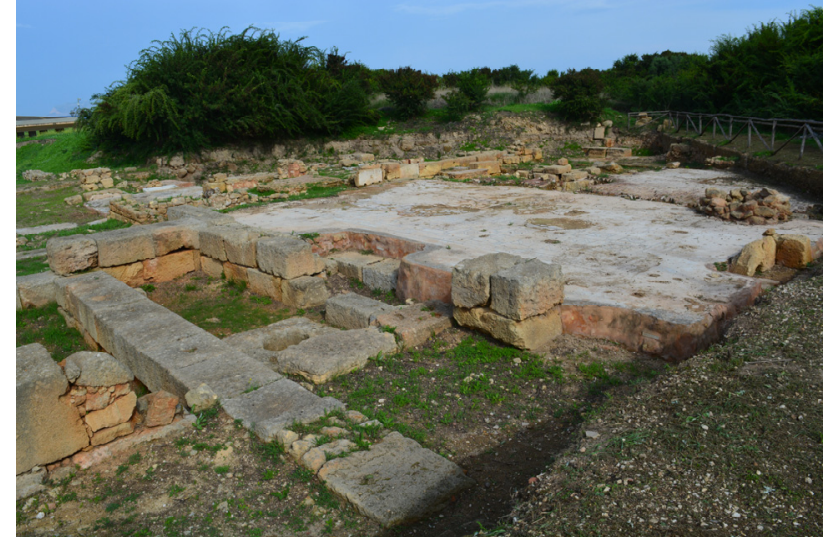

Figure 3. Remains of the so-called "Temple of Isis".

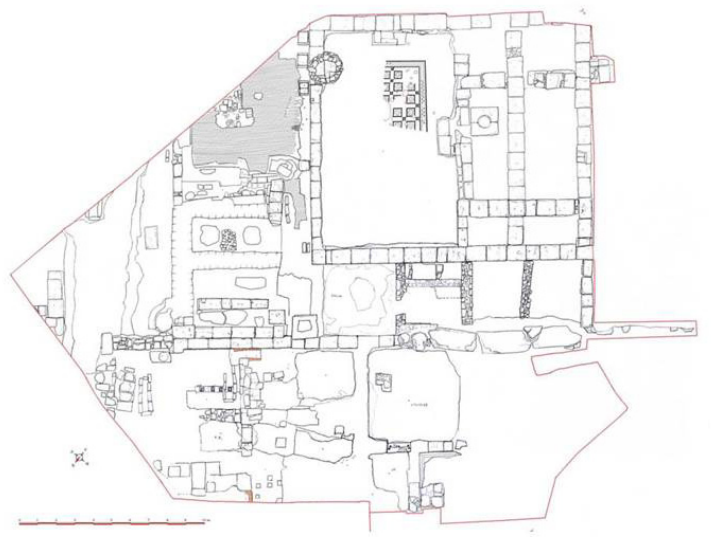

Figure 4. "Temple of Isis” plan (from Giglio, 2012)

Building plan was divided into three interconnected rooms (Figure 4). The central room is paved with a polychrome mosaic $(7.80 \mathrm{~m} \times 12.20 \mathrm{~m})$ with geometric decoration, widely patched in the past with inserts of marble slabs. A small podium is attached to the back wall on which a female statue could be stand (Figure 5). The northern room, perhaps an external portico, is characterized by an opus spicatum floor $(6.25 \mathrm{~m} \mathrm{x}$ $6.85 \mathrm{~m})$, built with small bricks arranged in a herringbone pattern, severely damaged by post-abandonment spoiling (Figure 6). The southern room was totally destroyed in the past removing strata below the floor level, deleting any information about its interior aspect.

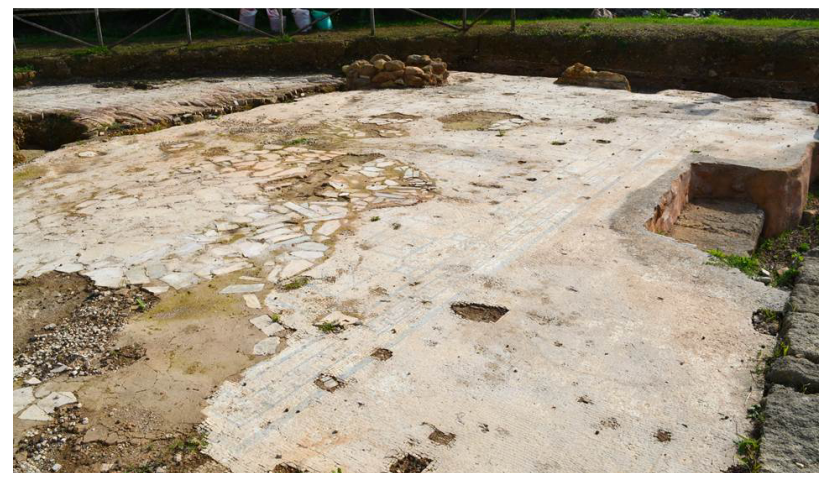

Figure 5. Mosaic of the central room.

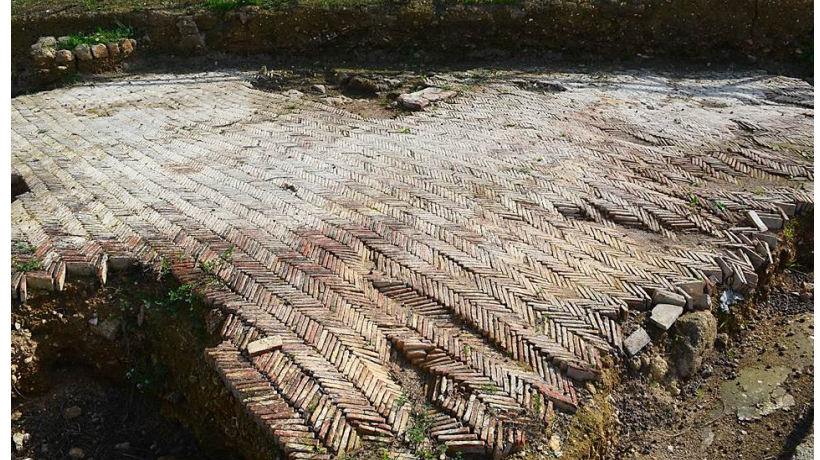

Figure 6. Opus spicatum floor of the northern room.

Polychrome marble fragments used as wall cladding, decorated stuccos, fragments of several sculptures and marble inscriptions found out during excavations, testify the relevance of the archaeological context.

Unfortunately, the reuse of the area as a necropolis since the $\mathrm{V}$ century A.D. and the consistent masonry spoiling have sensibly shattered the floors integrity.

For conservative reasons, both floors were covered after the end of the excavation in 2008. Covering removal before the survey showed several deterioration features, as the collapse of the surface mantle until the loss of the mosaic tesserae and of the small bricks of opus spicatum. Causes are due to the collapse of overlying structures, vegetation, but also to the typical decomposition of preparation layers.

\section{THE SURVEY}

Floors survey was conducted by means a close-range photogrammetric method, in order to acquire a 3D model of the existing structures and obtain an ortho-image with a high level of detail to employ in interpretation and reconstruction phases. Before the survey, several critical conditions to the fieldwork were identified, especially superficial shadows, mostly along the eastern side, due to the lower level of our structures respect to the limits of the excavation area.

Images acquisition has been carried out using a Nikon D5200 digital camera equipped with a $24-55 \mathrm{~mm}$ lens and pixel size of $3.9 \mu \mathrm{m}$ with an effective resolution of 6000 pixels $\mathrm{x} 4000$ pixels. A camera-to-object distance of $3 \mathrm{~m}$ and a focal length of $24 \mathrm{~mm}$ were chosen for image acquisition in order to obtain a Ground Sample Distance (GSD) of about $0.5 \mathrm{~mm}$ (Figure 7). An image coverage of about $3 \mathrm{~m} \times 2 \mathrm{~m}$ was obtained for each image.

A nadiral stereoscopic coverage was planned to provide a forward and side overlap of $70 \%$ (Figure 8 ). Images were taken with a camera mounted on a telescopic pole, with the camera sensor almost parallel to the floor plan (Figure 9). During the images acquisition, the lens was set to manual focus after adjusting it to the camera-to-object distance of $3 \mathrm{~m}$.

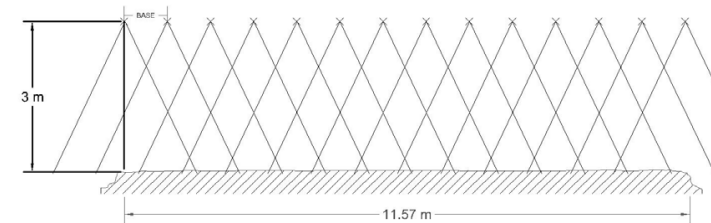

Figure 7. Cross-section view of camera network geometry for mosaic and opus spicatum floor. 


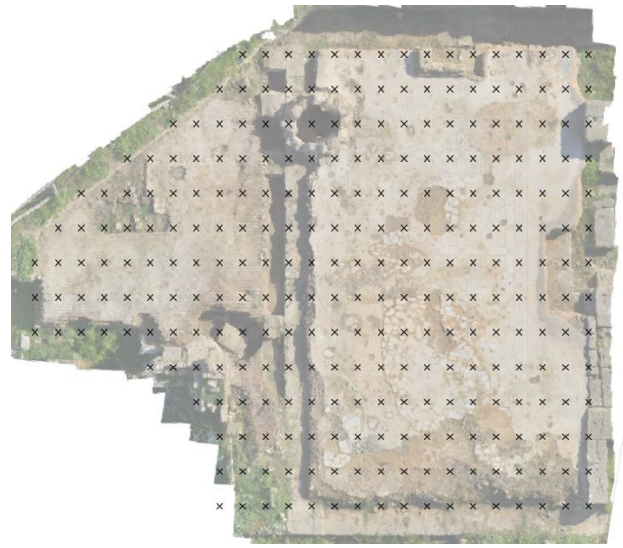

Figure 8. Planimetric view of camera network geometry for mosaic and opus spicatum floor survey.

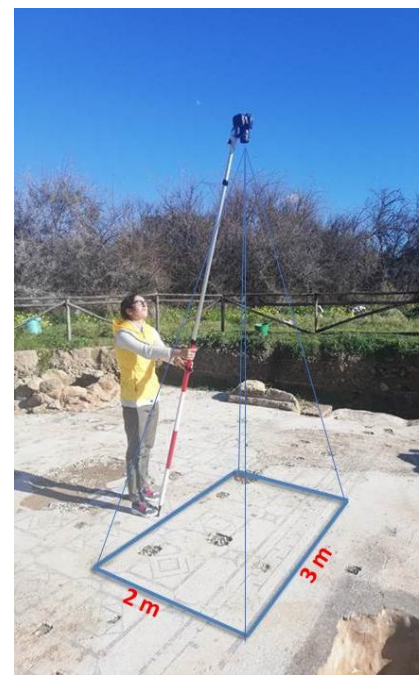

Figure 9. Telescopic pole image acquisition with the image projection on the floor.

Additional convergent strips along the edges were also carried out in correspondence of northern and western area to increase data redundancy. A total of 328 images were needed to survey an area of approximately $177 \mathrm{~m}^{2}$. Table 1 shows the main parameters of image acquisition.

\begin{tabular}{|l|c|l|c|}
\hline Number of images & 328 & Coverage area & $117 \mathrm{~m}^{2}$ \\
\hline $\begin{array}{l}\text { Camera-to-object } \\
\text { distance }\end{array}$ & $3.08 \mathrm{~m}$ & Tie points & 205.554 \\
\hline GSD & $0.42 \mathrm{~mm} / \mathrm{pix}$ & Reprojection error & $0.46 \mathrm{pix}$ \\
\hline
\end{tabular}

Table 1. Main parameters of the image acquisition.

Some points, using coded and no-coded targets, have been placed on the floors where tesserae and bricks were lost. The topographic survey was carried out to measure the coordinates of the targets by means of a Leica TPS 1105 total station. Overall 38 points were measured and used as Ground Control Points (GCPs) and as Check Points (CPs) in the orientation phase.

The images processing has been done, through the typical $\mathrm{SfM} /$ photogrammetry workflow, using the commercial software package Agisoft Metashape Professional (v.1.5.1 build 7618). No camera parameters were estimated before the survey, as instead suggested by Lo Brutto and Dardanelli (2017); they were automatically computed by Agisoft Metashape software during the orientation phase. As in the previous versions (Agisoft Photoscan), the software allows processing images step-by-step, calculating automatically internal and external camera orientation parameters (during "photo alignment" process and "photo optimization" process), 3D point cloud, textured mesh and ortho-image. The "photo alignment" process (Figure 10) and the point cloud process were performed with the high-quality setting.

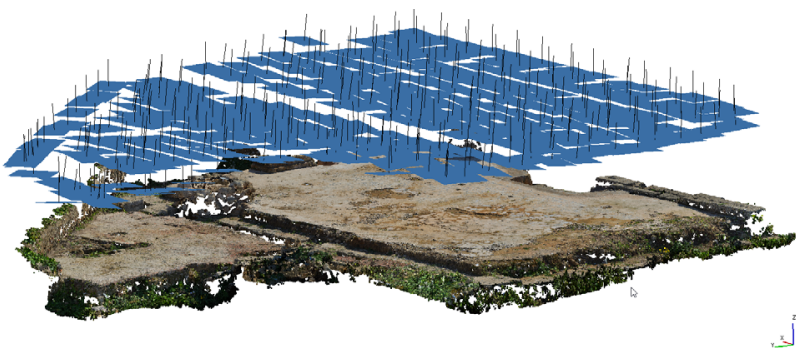

Figure 10. Schema of "photo alignment".

The evaluation of orientation results was done by the residuals of $23 \mathrm{GCPs}$ and $15 \mathrm{CPs}$. The result of the image orientation shows a root mean square error (RMSE) in XYZ of $\pm 2.1 \mathrm{~mm}$ for GCPs and of $\pm 3.1 \mathrm{~mm}$ for CPs (Table 2).

\begin{tabular}{|c|c|c|c|c|c|c|}
\hline & $\begin{array}{c}\text { Number of } \\
\text { points }\end{array}$ & $\begin{array}{c}\text { RMSE X } \\
{[\mathrm{mm}]}\end{array}$ & $\begin{array}{c}\text { RMSE Y } \\
{[\mathrm{mm}]}\end{array}$ & $\begin{array}{c}\text { RMSE Z } \\
{[\mathrm{mm}]}\end{array}$ & $\begin{array}{c}\text { RMSE } \\
\mathbf{X Y} \\
{[\mathrm{mm}]}\end{array}$ & $\begin{array}{c}\text { RMSE } \\
\mathbf{X Y Z} \\
{[\mathrm{mm}]}\end{array}$ \\
\hline GCPs & 23 & 1.31 & 0.97 & 1.24 & 1.63 & 2.05 \\
\hline CPs & 15 & 1.7 & 0.98 & 2.34 & 1.97 & 3.06 \\
\hline
\end{tabular}

Table 2. Residuals of the image orientation.

Following the processing workflow, several products were generated:

- a dense point cloud of $277 \mathrm{Ml}$ of points with an average resolution of $1 \mathrm{~mm}$;

- a texturized mesh of $18 \mathrm{Ml}$ faces;

- an ortho-image with a resolution of $1 \mathrm{~mm}$, preserving a suitable level of detail for the interpretation analysis and 2D reconstruction of the floors decoration schemes.

\section{THE INTERPRETATION}

Interpretation phase was directed to provide quantitative data, about sizes and decorative scheme of both surfaces, and qualitative information, such as colour and conservation status of the structures. Proceeding from overall to detailed analysis, information such as construction lines and decorative scheme were defined and re-drawing on the ortho-image.

From a qualitative point of view, the overall analysis has highlighted several critical issues for surface layers integrity, connected to the degradation of the lower preparation layers. Ancient floors are composed by a set of layers, made with limebased mortars and addition of various aggregates, on which the tesserae or the bricks were applied; each layer is subject to deterioration that can lead to the pulverization of the constituent material, with the consequent voids formation and the surface collapse. However, other causes seem to have contributed to the 
progressive damage of our ancient floors: downfalls of overlying structures (roofs and upper floors), fires, vandalism, structures reuse or growth of vegetation due to bad conservation. Certainly due to the re-use of the building, perhaps in the medieval age, are several insertions of marble slabs on the mosaic, and the positioning of a circular silos, probably for foodstuffs conservation, in the northeast corner of the room.

For the colors of the floors, unfortunately, at the present is not possible to appreciate the original chromatic characteristics; due to the considerable instability of the various surface components for which a thin layer of liquid cement has been laid on the floors as consolidating. This solution - to avoid the progressive loss of the surface materials - has irreversibly compromised the color visibility, which survived below the greyish patina. Some parts of the opus spicatum have been spared from the liquid cement and clearly show the original color of the bricks, with variations from deep red to grey. The mosaic, instead, was completely covered, thus avoiding chromatic characteristics acquisition from the reference orthoimages.

From a quantitative point of view, more closely linked to the measurement and acquisition of geometric shapes, the detailed analysis has allowed recognizing the recurring geometric shapes that are the basis of the construction scheme of both floors.

The mosaic scheme is based on systematic repetition of two squares, measured $0.41-0.42 \mathrm{~m}$ per side, characterized by square and rhombus alternated, both of $0.25 \mathrm{~m}$ each per side. They are divided by a series of four-pointed stars connecting vertices squares (Figure 11)

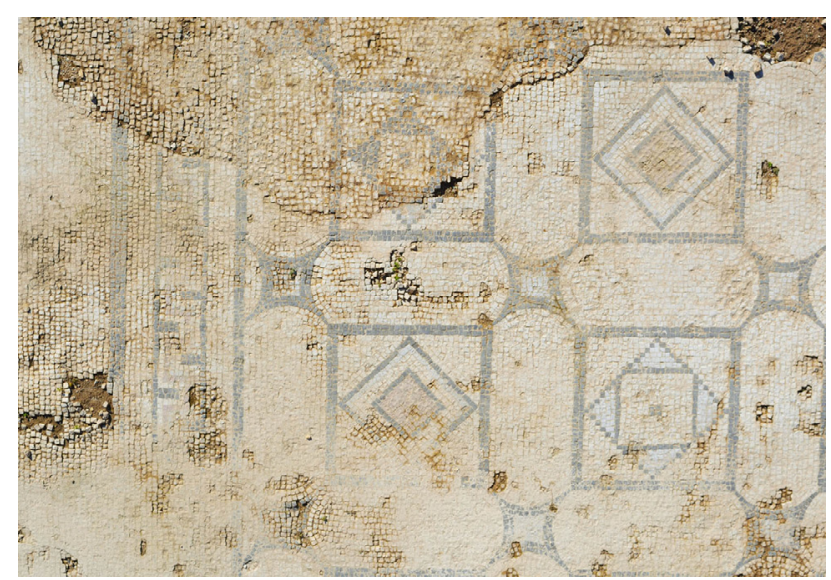

Figure 11. Mosaic decorative elements.

Each tessera size, approximately $1 \mathrm{~cm}$ per side, allows estimating the number of tesserae required for the realization of decorative elements (for example the length of $41 \mathrm{~cm}$ of a square module side corresponding to 41 tesserae). The sequence of 72 squares $(12 \times 6)$ is defined inside a frame of $8.35 \mathrm{~m} \mathrm{x} 4.60$ mwith pseudo-meander motifs (Figure 12).

Decorative elements are placed almost in the room centre, on a uniform background made with white local stone tesserae. The extension of the entire floor, and therefore of the whole room, is $11.60 \mathrm{~m} \mathrm{x} 7 \mathrm{~m}$.

Opus spicatum is characterized instead by a series of bricks, 11 $\mathrm{cm}$ long, placed obliquely in a systematic way in strips $15 \mathrm{~cm}$ wide, for the whole width of the space (Figure 13). Two notcovering zone, due to unknown structures, are identified in a central position. The reconstructed dimensions evaluated for the entire floor are $6.28 \mathrm{~m}$ width and $11.50 \mathrm{~m}$ length (Figure 14).

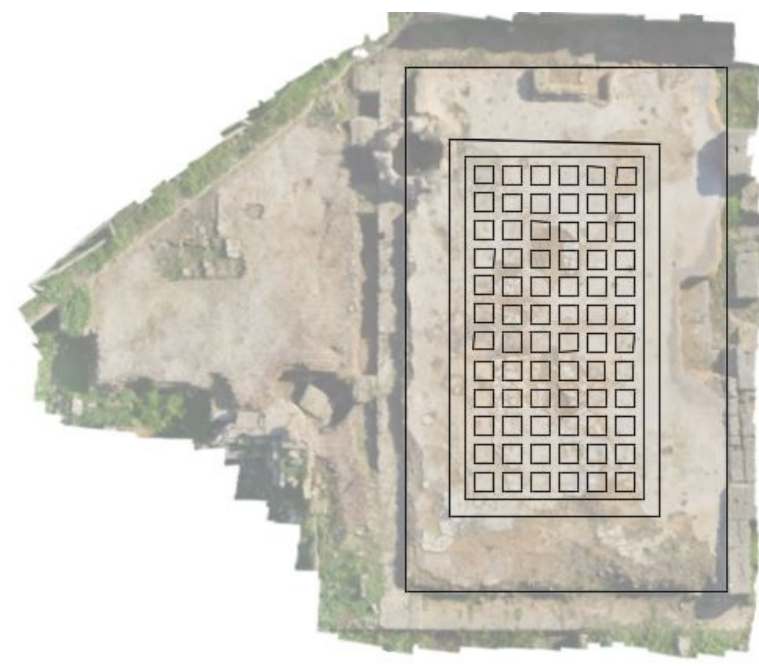

Figure 12. Mosaic geometrical scheme.

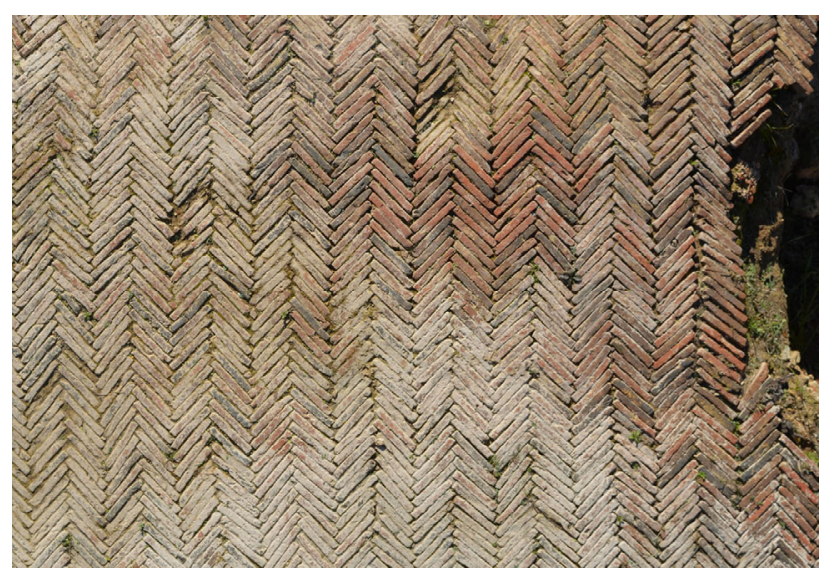

Figure 13. Opus spicatum pattern.

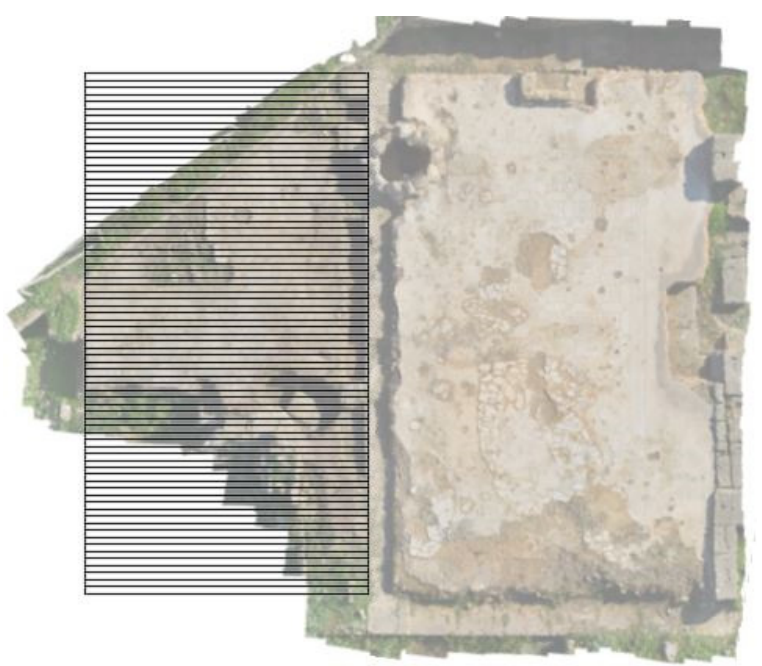

Figure 14. Opus spicatum geometrical scheme and reconstructed dimensions of the entire floor.

\section{THE VIRTUAL RECONSTRUCTION}

The level of detail of a virtual product is related to the aims of the work. Simplified reconstruction can be produced acceptable results if a simple visualization of the virtual object is required. If instead, the purpose of VR is a detailed reconstruction of all 
the features, e.g. for planning restoration activities, no geometric shapes or decorative elements can be simplified. Furthermore, in the case where the object has a strong threedimensionality its 3D model assumes a fundamental relevance; in the case of predominantly flat surfaces, such as ancient mosaics or floors, 2D survey data (such as the ortho-image) assume instead prevalent importance. For these reasons, the VR of the mosaic and of the opus spicatum was mainly based on the ortho-image obtained from the photogrammetric survey. VR of the floors was conducted in a rigorous way, respecting geometry and chromatic features.

\subsection{Reconstruction process}

The first problem in the VR process was the reproduction of the colours of the original floors. Color reproducibility issue is relevant to our purposes in order to obtain a reconstruction that is as scientifically reliable as possible. The characteristics of the site and the object - such as the type of light source or the response of the material to the optical sensor - can affect the perception of color, often distorting it. To reproduce colors in the most faithful way to historical reality, the chromatic information were managed obtaining color characteristics from the ortho-image or from more available sources, e.g. photos, drawings and documents acquired during excavations.

Opus spicatum preserves small unmodified parts, from which to sample useful chromatic information for VR, while mosaic has not kept any part with the original colors. So, a small part of the opus spicatum in which the color is preserved was sampled, restored and used to create a strip of regular thickness of $15 \mathrm{~cm}$; this regular strip was extended to the width of the entire reconstructed floor $(6.28 \mathrm{~m})$. This element, that can be considered as a "modular pattern", was adapted to the grid of the scheme proposed in the interpretative phase (Figure 14).

The mosaic reconstruction process was firstly done tessera by tessera. The entire mosaic is composed by 4-colour tesserae: black, white, light blue and red. Different colours shades enable to recreate superficial ruffle that is often characteristic of these types of ancient floors, increasing the real feel with the artefact. Color sampling was conducted acquiring chromatic information by means of a couple of high-resolution photos acquired during excavations, where color are still visible. So, two tesserae for each colour with slight tonal variations were used as sample to obtain good results on colour reproducibility (Figure 15). On the same photos, each main decorative element - the two squares, the four-pointed star and a portion of a frame decorated with a pseudo-meander motif - was "virtually restored", replacing tesserae patterns where the original are lost. It was thus possible to reconstruct each main decorative element and adapt them into a selected area of the ortho-image (Figure 16).

For the white mosaic background, the virtual restoration was directly carried out by creating a homogeneous crosshatch on the ortho-image, using previously acquired white tesserae patterns. A transparency value of around $20 \%$ has also been maintained for the background and decorative elements, in order to achieve a less invasive restoration.

The selected area of the ortho-image has been reproduced and adapted on the entire ortho-image respecting the predefined reconstruction scheme and avoiding an unreal reconstruction (Figure 17).

Finally, based on the original ortho-images, two new detailed textures have been reconstructed for both floors, to be used for future VR proposals in a 3D environment.
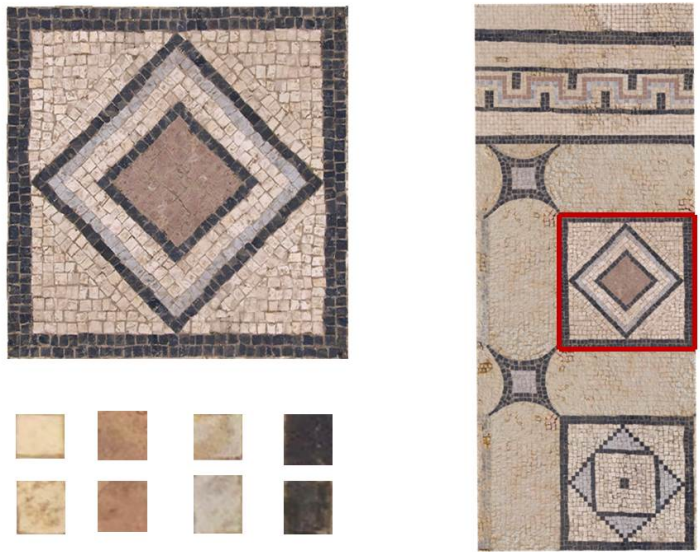

Figure 15. Different samples of tesserae used for each element.

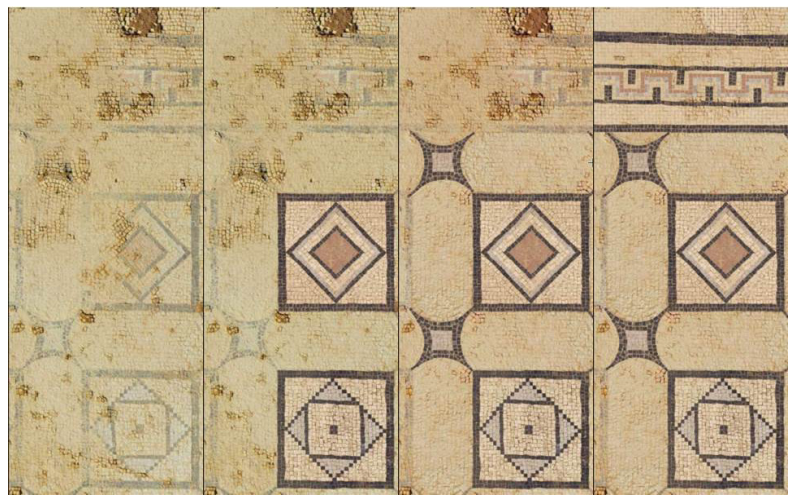

Figure 16. Steps of mosaic pattern restoration.

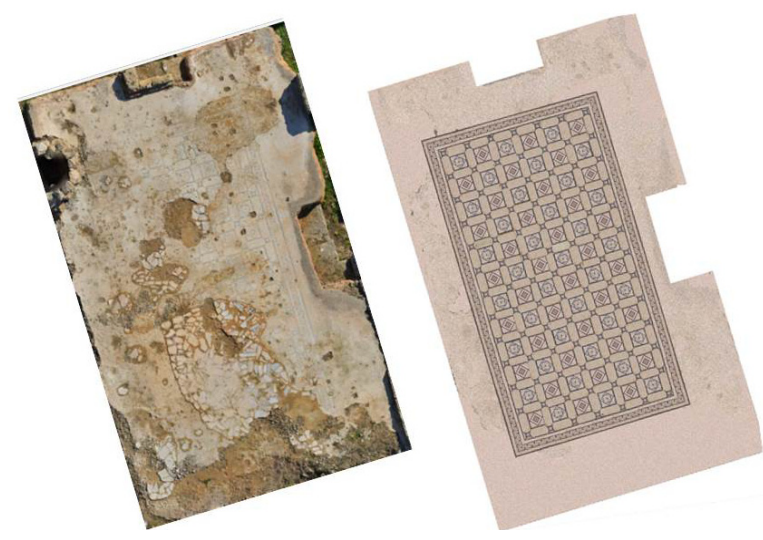

Figure 17. Mosaic ortho-image before and after the virtual reconstruction.

\subsection{D modelling and texturing}

The next step was to align the new textures, created by virtual restoration, to the position of on the original mesh acquired by the photogrammetry survey, enabling views comparison between the existing structures and hypothetical reconstruction. Replacing the photo-realistic texture of the 3D model with the new textures, created respecting exactly the original measurements, it was possible re-texturize the 3D model, maintaining the precise relationship between the position of the 3D model and the new textures. They were aligned using the 
original position and orientation of the old texture, replaced by new textures exactly matched to the original 3D model (Figure 18).

This test shows a first visual representation in 3D environment of both surfaces reconstruction, where the original colors can be seen. However, this is an incomplete representation, because is based on the structures real state. This simple visualization can be directly used as a support for educational proposals or for restoration activities, promoting potentiality in protection and enhancement fields for a single object or an entire context.

A further step will be to use the new textures during the virtual modeling of the entire "Temple of Isis" complex. Once the perimeter walls of each room will be modeled/reconstructed, as well as recreated the respective floors regularizing the current deformations through 3D modeling, our new textures could be used in their reconstructed extension.

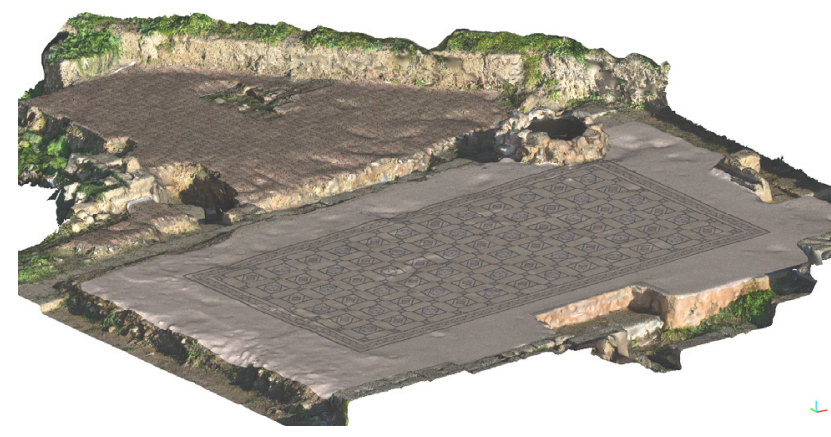

Figure 18. Overlap of the new restored textures to the original 3D model.

\section{CONCLUSIONS}

In this paper, a 3D virtual reconstruction of a mosaic and opus spicatum floors (two of the most common types of floors in Roman Age) was obtained as the first step of the project that aims to re-built the entire "Temple of Isis" complex in a 3D digital environment.

Work shows how to generate a high-quality 3D model, by a photogrammetric survey, that can be used for different purposes, such as a detailed virtual model reconstruction. Starting from a detailed survey, that shows real structures conditions, it was possible to acquire data (e.g. plans, sections, ortho-images) useful to perform interpretative analyses and reconstruction hypotheses.

In our case, the geometrical decorative elements of the two floors were identified and reconstructed. However, it should be underlined that the proposed approach can only be applied in cases where reconstruction process concern surfaces decorated with geometric patterns, that can be reproduced sequentially, and for which a sufficiently large portion is preserved to allow scheme reconstruction. In other cases, such as for figurative mosaics in which the surface is partially preserved, it might be more difficult to formulate reliable hypotheses around the virtual reconstruction without additional sources (e.g. photos, drawings, description).

\section{ACKNOWLEDGEMENTS}

For the realization of this work, the authors would like to express our gratitude to the "Polo Museale di Trapani", especially to Anna Maria Parrinello and Maria Grazia Griffo of the "Lilibeo - Baglio Anselmi Regional Archaeological
Museum". Further thanks are due to Rossella Giglio for the supply of the excavation documents.

\section{REFERENCES}

Adami, A., Fassi, F., Fregonese, L., Pianandrea, M., 2018. Image-based techniques for the survey of mosaics in the St Mark's Basilica in Venice. Virtual Archaeology Review, 9(19), $1-20$.

Agnello, F., Albano, S., Avella, F., Cannella, M., Giordano, G., 2015. Integrated surveying and modeling techniques for the documentation and visualization of three ancient houses in the Mediterranean area. SCIentific RESearch and Information Technology, 5(2), 33-48.

Aicardi, I., Chiabrando, F., Lingua, A., Noardo F., 2018. Recent trend in cultural heritage 3D survey: the photogrammetric computer vision approach. Journal of Cultural Heritage, 32, 257-266.

Ajioka, O., Hori, Y., 2014. Application of SfM and laser scanning technology to the description of mosaics piece by piece. Int. Arch. Photogramm. Remote Sens. Spat. Inf. Sci., XL (5), 23-28.

Arza-García, M., Gil-Docampo, M., Ortiz-Sanz, J., 2019. A hybrid photogrammetry approach for archaeological sites: Block alignment issues in a case study (the Roman camp of A Cidadela). Journal of Cultural Heritage, in press.

Benyoussef, L., Derrode, S., 2011. Analysis of Ancient Mosaic Images for Dedicated Applications. In: Stanco F., Battiato S. (eds), Digital Imaging for Cultural Heritage Preservation: Analysis, Restoration, and Reconstruction of Ancient Artworks, 453-478.

Brumana, R., Oreni, D., Caspani, S., Previtali, M., 2018. Virtual museums and built environment: Narratives and immersive experience via multi-temporal geodata hub. Virtual Archaeology Review, 9 (19), 34-49.

D'Amelio, S., Lo Brutto, M., 2009. Close range photogrammetry for measurement of paintings surface deformation. Int. Arch. Photogramm. Remote Sens. Spatial Inf. Sci, XXXVIII-5/W1, 1-6.

Demetrescu, E., 2015. Archaeological Stratigraphy as a Formal Language for Virtual Reconstruction. Theory and Practice. Journal of Archaeological Science, 57, 42-55.

Demetrescu, E., Ferdani, D., Dell'Unto, N., Touati, A.M., Lindgren, S., 2016. Reconstructing the original splendor of the House of Caecilius Iucundus. A complete methodologhy for virtual archaeology aimed at digital exhibition. SCIentific RESearch and Information Technology, 6(1), 51-66.

Demetrescu, E., Fanini, B., 2017. A white-box framework to oversee archaeological virtual reconstructions in space and time: methods and tools. Journal of Archaeological Science: Reports, 14, 500-514.

Demetrescu, E., 2018. Virtual Reconstruction as a Scientific Tool: The Extended Matrix and Source-Based Modelling Approach, In: Münster S., Friedrichs K., Niebling F., SeidelGrzesińska A. (eds), Digital Research and Education in 
Architectural Heritage, Communications in Computer and Information Science, 817, 102-116.

Denker, A., 2017. Rebuilding Palmyra virtually: recreation of its former glory in digital space. Virtual Archaeology Review. 8(17), 20-30.

Doerr, M., 2003. The CIDOC Conceptual Reference Module. An Ontological Approach to Semantic Interoperability of Metadata. AI Magazine, 24 (3), 75-92.

Gabrielli, R., Portarena, D., Franceschinis, M., 2017. Tecniche di documentazione dei tappeti musivi dal sito archeologico di Umm Al-Rasas - Kastron Mefaa (Giordania). Archeologia e Calcolatori, 28, 201-218.

Giglio, R., Cerniglia R., 2012. Lilibeo (Marsala). Risultati della campagna 2008. In: Ampolo C. (eds), Sicilia occidentale. Studi, Rassegne, Ricerche, 225-238.

Gonzalez-Perez, C., Martín-Rodilla, P., Parcero-Oubiña, C., Fábrega-Álvarez, P., Güimil-Fariña, A., 2012. Extending an abstract reference model for transdisciplinary work in cultural heritage. In: Research Conference on Metadata and Semantic Research, 190-201.

Harris, E.C., 1979. Principles of Archaeological Stratigraphy. Academic Press.

Hatzopoulos, J.N., Stefanakis, D., Georgopoulos, A., Tapinaki, S., Pantelis, V., Liritzis, I., 2017. Use of various surveying technologies to $3 \mathrm{D}$ digital mapping and modelling of Cultural Heritage structures for maintenance and restauration purposes: the Tholos in Delphi, Greece. Mediterranean Archaeology and Archaeometry, 1(73), 311-336.

Lo Brutto, M., Dardanelli, G., 2017. Vision metrology and Structure from Motion for archaeological heritage 3D reconstruction: a Case Study of various Roman mosaics, Acta IMEKO, 6(3), 35-44.

Monti, M., Maino, G., 2018. Non-metric digital reconstruction of Roman mosaics excavated in the city of Ravenna (Italy). Virtual Archaeology Review, 9 (19), 66-75.

Remondino, F., Nocerino, E., Toschi, I., Menna, F., 2017. A critical review of automated photogrammetric processing of large datasets. Int. Arch. Photogramm. Remote Sens. Spatial Inf. Sci., XLII-2/W5, 591-599.

Remondino, F., Gaiani, M., Apollonio, F., Ballabeni, A., Ballabeni, M., Morabito, D., 2016. 3D documentation of 40 kilometers of historical porticoes - the Challenge. The Int. Arch. Photogramm. Remote Sens. Spatial Inf. Sci., XLI/B5, 711-718.

Santachiara, M., Gherardini. F., Leali. F., 2018. An Augmented Reality Application for the Visualization and the Pattern Analysis of a Roman Mosaic, IOP Conference Series: Materials Science and Engineering, 364, 1-8.

Sapirstein, P., Murray S., 2017. Establishing Best Practices for Photogrammetric Recording During Archaeological Fieldwork. Journal of field Archaeology, 42 (4), 337-350.
The London Charter, 2009. The London Charter - For the Computer-based visualization of Cultural Heritage. Draft 2.1, 7 February 2009, http://www.londoncharter.org/.

The Seville Principles, 2011. The Seville Principles International Principles of Virtual Archaeology, Final Draft, $\mathrm{http}: / /$ smartheritage.com/seville-principles/seville-principles

Younes, G., Kahil, R., Jallad, M., Asmar, D., Elhajj, I., Turkiyyah, G., Al-Harithy, H., 2017. Virtual and augmented reality for rich interaction with cultural heritage sites: A case study from the Roman Theater at Byblos. Digital Applications in Archaeology and Cultural Heritage, 5, 1-9. 